Research

Open Access

\title{
Phosphodiesterase 4 inhibition but not beta-adrenergic stimulation suppresses tumor necrosis factor-alpha release in peripheral blood mononuclear cells in septic shock
}

\author{
Andreas Link, Simina Selejan, Christoph Maack, Monika Lenz and Michael Böhm
}

Klinik für Innere Medizin III, Universität des Saarlandes, 66421 Homburg/Saar, Germany

Corresponding author: Andreas Link, link@med-in.uni-saarland.de

Received: 22 Sep 2008 Revisions requested: 20 Oct 2008 Revisions received: 19 Nov 2008 Accepted: 17 Dec 2008 Published: 17 Dec 2008

Critical Care 2008, 12:R159 (doi:10.1186/cc7158)

This article is online at: http://ccforum.com/content/12/6/R159

(c) 2008 Link et al.; licensee BioMed Central Ltd.

This is an open access article distributed under the terms of the Creative Commons Attribution License (http://creativecommons.org/licenses/by/2.0), which permits unrestricted use, distribution, and reproduction in any medium, provided the original work is properly cited.

\begin{abstract}
Introduction Stimulation of beta ${ }_{2}$-adrenergic receptors $\left(\beta_{2}\right.$ ARs) inhibits tumor necrosis factor-alpha (TNF- $\alpha$ ) release in monocytes. In septic shock, endogenous catecholamines induce $\beta_{2}$-AR downregulation, leading to an increased TNF- $\alpha$ release. The aims of this study were to analyze the molecular mechanisms of $\beta$-adrenergic downregulation and to explore therapeutic interventions with maintained anti-inflammatory efficacy in septic shock using the inhibition of phosphodiesterase 4 (PDE4).

Methods We conducted in vitro stimulation of peripheral blood mononuclear cells of healthy volunteers $(n=20)$ and patients with septic shock $(n=20)$ with lipopolysaccharide (LPS) or Staphylococcus aureus enterotoxin B (SEB) without or with isoprenaline, forskolin (an activator of adenylate cyclase), or ropipram (an inhibitor of PDE4). We also conducted flow cytometric analysis of Toll-like receptor (TLR) 4 and TLR2 surface expression and intracellular TNF- $\alpha$ production of untreated and stimulated CD $14^{+}$monocytes. Protein expression of $\beta$-ARs, of $G$ proteins, of adenylate cyclase, and of TLRs was measured by Western blotting.
\end{abstract}

Results Investigations were done by LPS $(100 \mathrm{ng} / \mathrm{mL})$ or SEB (10 ng/mL) when TLR4 and TLR2 were maximally expressed. LPS- or SEB-treated CD14+ monocytes of healthy volunteers were able to produce TNF- $\alpha$. This effect was attenuated by isoprenaline, forskolin, or rolipram in a concentration-dependent manner. In CD14+ monocytes of patients with septic shock, the anti-inflammatory effect of isoprenaline was completely blunted whereas efficacy of forskolin and rolipram was maintained. $\mathrm{CD}_{14}{ }^{+}$monocytes of healthy volunteers were compared with patients with septic shock: protein expression of $\beta_{2}$-ARs was reduced and inhibitory $G$ protein was increased, whereas no changes in adenylate cyclase and stimulatory $G$ protein were found.

Conclusions In septic shock, the anti-inflammatory effects of catecholamines are blunted by downregulation of $\beta_{2}$-ARs and upregulation of the inhibitory $\mathrm{G}$ protein in CD14+ monocytes. Beta-adrenergic downregulation is overcome by inhibitors of PDE4. These results provide a mechanistic rationale for the therapeutic use of selective PDE4 inhibitors in the treatment of septic shock.

\section{Introduction}

Severe sepsis and septic shock are systemic responses to infection and represent predominant causes of death in intensive care units $[1,2]$, with the incidence of sepsis steadily increasing over the past decades [3]. Monocytes are activated by surface receptors such as Toll-like receptors (TLRs) through recognition of pathogen-derived exogenous ligands: lipopolysaccharides (LPSs), Staphylococcus aureus entero- toxin B (SEB), other peptidoglycans, and oligonucleotides. TLR-mediated signaling pathways induce proinflammatory cytokine expression like tumor necrosis factor-alpha (TNF- $\alpha$ ) and interleukin-6, triggering the systemic inflammatory response syndrome and the development of septic shock $[4,5]$.

$\beta$-AR: beta-adrenergic receptor; AC: adenylate cyclase; Cy5: cyanine $5 ; \mathrm{EC}_{50}: 50 \%$ of the maximal effect; FACS: fluorescence-activated cell sorting; FITC: fluorescein isothiocyanate; $G_{i \alpha}$ : alpha-subunit of the inhibitory $G_{\text {protein; }} G_{\mathrm{s} \alpha}$ : alpha-subunit of stimulatory $G$ protein; LPS: lipopolysaccharide; PBMC: peripheral blood mononuclear cell; PDE4: phosphodiesterase 4; PE: phycoerythrin; SEB: Staphylococcus aureus enterotoxin B; TLR: Tolllike receptor; TNF- $\alpha$ : tumor necrosis factor-alpha. 
It has long been recognized that $\beta$-adrenergic stimulation suppresses LPS-induced TNF- $\alpha$ release from blood cells in vitro and in vivo [6] and thus could ameliorate the inflammatory response. In severe sepsis and septic shock, neuroendocrine systems are activated. Sympathetic activation is associated with increasing plasma concentrations of epinephrine and norepinephrine [7] and desensitization of the $\beta$-adrenergic system (that is, downregulation of $\beta$-adrenergic receptor [ $\beta$ $\mathrm{AR}$ ] density as shown for the $\beta_{1}$-ARs in chronic heart failure [810]). Also, in patients with septic shock, the hemodynamic response to $\beta_{1}$-AR agonists was impaired, and in peripheral blood mononuclear cells (PBMCs), a decreased $\beta_{2}$-AR-mediated cAMP production was found [11-13].

In septic shock, patients require intravenous catecholamines, which may aggravate $\beta$-adrenergic desensitization, potentially leading to further deterioration of the hemodynamic situation and overwhelming PBMC TNF- $\alpha$ release. Thus, an attractive therapeutic approach to exert cAMP-mediated anti-inflammatory effects despite $\beta$-AR desensitization would be to inhibit phosphodiesterase 4 (PDE4) by rolipram $[14,15]$. The present study was designed (a) to analyze whether $\beta$-AR-mediated inhibition of LPS-induced TNF- $\alpha$ expression is blunted in PBMCs of human patients with septic shock, (b) to clarify which mechanisms of desensitization are involved, and (c) to determine whether the PDE4 inhibitor rolipram is able to suppress LPS-induced TNF- $\alpha$ expression.

\section{Materials and methods}

After approval of the institutional review board and informed consent of all of the study participants were received, blood samples were obtained from 20 healthy volunteers without any signs of infection and from 20 patients with septic shock. Because of age-related differences in leukocyte function, the healthy control group was age-matched (median of 49 years and range of 21 to 75 years). All patients fulfilled criteria of septic shock defined as sepsis with at least one organ dysfunction and the requirement of catecholamine therapy [16]. Demographic and clinical characteristics of patients are presented in Table 1.

\section{Cell preparation, stimulation, and culture conditions}

PBMCs were isolated with the use of a Ficoll density gradient (Biochrom, Berlin, Germany) within 30 minutes after collecting peripheral venous blood from volunteers or septic patients. Cells were cultured at $3 \times 10^{6}$ cells per milliliter in RPMI 1640 (PAA Laboratories, Cölbe, Germany) supplemented with $5 \%$ fetal calf serum (Biochrom), $2 \mathrm{mmol} / \mathrm{L}$ glutamine, and antibiotics. Culture media and all reagents were tested for the absence of endotoxins. All incubations were carried out in a humidified incubator at $37^{\circ} \mathrm{C}, 21 \% \mathrm{O}_{2}$ and $5 \% \mathrm{CO}_{2}$.

PBMCs were analyzed for (a) changes of TLR4 expression in response to increasing LPS $(0.1$ to $10,000 \mathrm{ng} / \mathrm{mL})$ and isoprenaline $(0.0001$ to $10 \mu \mathrm{mol} / \mathrm{L})$ concentrations and time
Table 1

Patients' demographic data, clinical characteristics, and survival

\begin{tabular}{|c|c|}
\hline \multicolumn{2}{|l|}{ Demographic data } \\
\hline Age in years, median (range) & 52 (25 to 73$)$ \\
\hline Female/male, number & $10 / 10$ \\
\hline \multicolumn{2}{|l|}{ Septic shock: reasons } \\
\hline Pneumonia & 8 \\
\hline Urosepsis & 4 \\
\hline Cholangitis & 4 \\
\hline Endocarditis & 3 \\
\hline Catheter-associated & 3 \\
\hline \multicolumn{2}{|l|}{ Pathogen } \\
\hline Staphylococcus epidermidis, number & 6 \\
\hline Staphylococcus aureus, number & 2 \\
\hline Haemophilus influenca, number & 4 \\
\hline Enterococcus faecalis, number & 3 \\
\hline Escherichia coli, number & 3 \\
\hline Pseudomonas aeruginosa, number & 2 \\
\hline \multicolumn{2}{|l|}{ Severity-of-illness scores } \\
\hline APACHE II score, median (range) & $30(18$ to 52$)$ \\
\hline SAPS II, median (range) & 42 (32 to 66$)$ \\
\hline \multicolumn{2}{|l|}{ Catecholamine therapy } \\
\hline $\begin{array}{l}\text { Dobutamine, number } \\
\text { Dose in } \mu \mathrm{g} / \mathrm{kg} \text { per minute (mean } \pm \mathrm{SD} \text { ) }\end{array}$ & $\begin{array}{c}20 \\
(6.4 \pm 2.9)\end{array}$ \\
\hline $\begin{array}{l}\text { Norepinephrine, number } \\
\text { Dose in } \mu \mathrm{g} / \mathrm{kg} \text { per minute (mean } \pm \mathrm{SD} \text { ) }\end{array}$ & $\begin{array}{c}16 \\
(0.2 \pm 0.2)\end{array}$ \\
\hline \multicolumn{2}{|l|}{ Outcome } \\
\hline ICU mortality rate, number (percentage) & $4(20)$ \\
\hline Hospital mortality rate, number (percentage) & $5(25)$ \\
\hline
\end{tabular}

APACHE, Acute Physiology and Chronic Health Evaluation; ICU, intensive care unit; SAPS, Simplified Acute Physiology Score; SD, standard deviation.

dependency (6, 12, and 24 hours), (b) changes of TLR2 expression in response to increasing SEB (0.1 to $10,000 \mathrm{ng} /$ $\mathrm{mL})$ and isoprenaline $(0.0001$ to $10 \mu \mathrm{mol} / \mathrm{L})$ concentrations and time dependency $(6,12$, and 24 hours), (c) changes of LPS-mediated TNF- $\alpha$ expression in the absence or presence of isoprenaline, rolipram, and forskolin (all 0.001 to $10 \mu \mathrm{mol} /$ $\mathrm{L})$, and (d) changes of SEB-mediated TNF- $\alpha$ expression in the absence or presence of isoprenaline, rolipram, and forskolin (all 0.001 to $10 \mu \mathrm{mol} / \mathrm{L}$ ).

Intracellular cytokine measurement by flow cytometry For cytokine expression, PBMCs were stimulated with LPS $(100 \mathrm{ng} / \mathrm{mL})$ or SEB $(10 \mathrm{ng} / \mathrm{mL})$ and reagents simultaneously 
and incubated for a total of 24 hours. Initially, Brefeldin A (10 $\mu \mathrm{g} / \mathrm{mL}$ ) (Sigma-Aldrich, Munich, Germany) was added to block extracellular secretion of cytokines. Cell fixation was done with $2 \mathrm{mM}$ EDTA (ethylenediaminetetraacetic acid) for 15 minutes for planned measurement of cytokine expression after 6 hours. Cell membranes were reversibly permeabilized with Saponine (0.1\%) (Sigma-Aldrich) in phosphate-buffered saline containing $5 \%$ milk powder and $0.1 \%$ bovine serum albumin (Sigma-Aldrich). Cell surface markers and intracellular cytokines were labelled with mouse anti-human antibodies conjugated to fluorescent dyes at saturating concentrations in permeabilization buffer. For staining of the cell surface markers of monocytes, we used anti-CD14-PE-Cy5 (anti-CD14-phycoerythrin-cyanine 5), anti-TLR4-FITC (anti-TLR4-fluorescein isothiocyanate), and anti-TLR2-FITC. For staining of intracellular monocyte cytokines, we used anti-TNF- $\alpha$-FITC. After 45 minutes of incubation at room temperature, cells were washed three times in permeabilization buffer and twice in fluorescence-activated cell sorting (FACS) buffer. Subsequently, stained antigens were fixed with $1 \%$ paraformaldehyde.

Measurements were performed on a Becton Dickinson FACScan flow cytometer (Becton Dickinson, Heidelberg, Germany) and the Cellquest software system (Becton Dickinson, Heidelberg, Germany). Monocytes were identified by forward and sideward scatter and CD14 positivity, and 10,000 events of CD14+ monocytes were gated. The data are shown as median fluorescence intensities of TNF- $\alpha$-producing CD14+ monocytes. This method allows a more complete analysis of the functional activity on a single-cell level compared with conventional methods, as described previously [17].

\section{Western blotting}

Monocytes were isolated from PBMCs by magnetic cell sorting using microbeads in accordance with the instructions of the manufacturer (Dynabeads Monocyte; Invitrogen Corporation, Carlsbad, CA, USA). Isolated monocytes are bead- and antibody-free with a purity of $\mathrm{CD} 14^{+}$monocytes of $95 \%$. These cells were separated in cytosol and membrane proteins, containing equal aliquots of denatured protein $(50 \mu \mathrm{g})$. Nonspecific binding was blocked by incubation with $5 \%$ nonfat dry milk for 1 hour at room temperature. Immunoblotting was performed using the following monoclonal antibodies: $\beta_{2}-A R$, adenylate cyclase $(A C)$, and $\alpha$-subunits of stimulatory $\left(G_{s \alpha}\right)$ and inhibitory $\left(G_{i \alpha}\right) G$ proteins. Equal loading of total protein was controlled by Poinceau red staining (Serva Electrophoresis, Heidelberg, Germany). The immunoreactive bands were quantified by two-dimensional densitometry using Multianalyst software (Bio-Rad Laboratories, München, Germany).

\section{Reagents and materials}

Standard reagents of the highest available quality were used. LPS (serotype Escherichia coli 055:B5), SEB (fragment 150161), isoprenaline, and forskolin were purchased from SigmaAldrich. Rolipram from A.G. Scientific (San Diego, CA, USA) was used. The drug concentrations that we used had no cytotoxic influence on the measured PBMCs. The following monoclonal antibodies were used: anti-CD14 PE-Cy5-labelled (clone RMO52, lot 06; Beckman Coulter, Krefeld, Germany), anti-TNF- $\alpha$ FITC-labelled (clone MAb11, lot 28687; BD Pharmingen, San Diego, CA, USA), anti-TLR4 (clone 76B357.1, lot 445414; Abcam, Cambridge, UK), anti-TLR2 (clone T2.5, lot 526240; Abcam), anti-AC (rabbit polyclonal $\lg \mathrm{G}$ ), anti- $\beta_{2}-A R$ (rabbit polyclonal $\lg \mathrm{G}$ ) from Santa Cruz Bio-

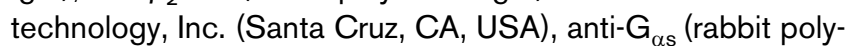
clonal lgG) from Upstate Biotechnology (Lake Placid, NY, USA), and anti-G $\mathrm{ai} 2_{2}$ generated as described previously [18].

\section{Statistics}

Data were calculated as mean \pm standard error of the mean and were analyzed using one-way analysis of variance. If variances differed significantly, the Mann-Whitney test was used. A $P$ value of less than 0.05 was considered significant. Concentrations inducing $50 \%$ of the maximal effect $\left(E_{50}\right)$ were calculated using GraphPad Prism software (GraphPad Software, Inc., San Diego, CA, USA).

\section{Results \\ Toll-like receptor surface expression on CD14+ monocytes of healthy volunteers}

To investigate whether TLRs could participate in the activation of normal monocytes, we analyzed TLR4 and TLR2 expression on CD14+ monocytes after stimulation with increasing doses of LPS or SEB. Cytometric analysis of TLR4 and TLR2 protein expression of untreated monocytes revealed a constitutive expression of both receptors (Figures 1 and 2). Treatment with LPS induced a significant upregulation of TLR4 expression even at low LPS concentrations, achieving a submaximal expression at $100 \mathrm{ng} / \mathrm{mL}$ (Figure 1a). CD14+ monocytes treated with increasing LPS concentrations had stimulatory effects of the TLR4 surface expression with an $\mathrm{EC}_{50}$ value of $10 \mathrm{ng} / \mathrm{mL}$. Therefore, all further investigations were done by $100 \mathrm{ng} / \mathrm{mL}$ LPS when TLR4 was maximally expressed. During a continuous LPS stimulation (100 $\mathrm{ng} / \mathrm{mL})$, TLR4 expression was significantly increased within 6 hours and the expression remained stable between 6 and 24 hours (Figure 1b). Treatment with isoprenaline did not alter the expression of TLR4 surface expression (Figure 1c).

Treatment with SEB induced no relevant changes of TLR2 expression even at low and high concentrations (Figure 2a). All further investigations were done by $10 \mathrm{ng} / \mathrm{mL}$ SEB when TLR2 was maximally expressed. During a continuous SEB stimulation (10 ng/mL), TLR2 expression remained unchanged between 6 and 24 hours (Figure 2b). Treatment with isoprenaline did not alter the expression of TLR2 surface expression (Figure 2c). 


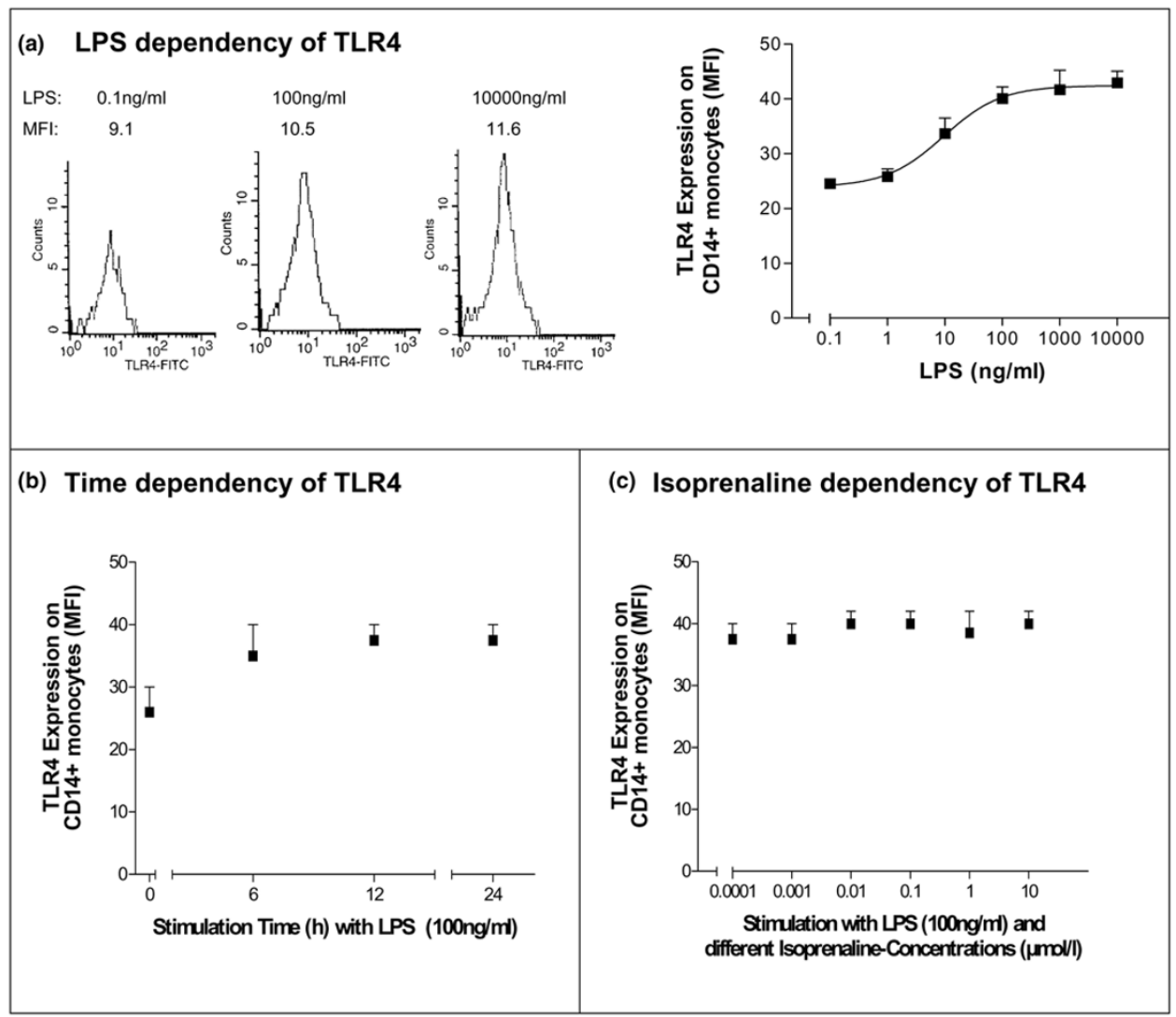

Modulation of Toll-like-receptor 4 (TLR4) surface expression on CD14+ monocytes of healthy volunteers $(n=20)$. Responses to $(a)$ increasing concentrations of lipopolysaccharide (LPS), (b) time dependency under continuous LPS stimulation (100 ng/mL), and (c) increasing concentrations of isoprenaline are shown. TLR4 expression was measured by flow cytometry, and histograms of median fluorescence intensity (MFI) and averages with standard error of the mean from all probands are shown. FITC, fluorescein isothiocyanate.

\section{Inhibition of LPS-/SEB-mediated tumor necrosis factor- alpha expression in CD14+ monocytes of healthy volunteers}

Incubation of PBMCs from healthy volunteers with LPS for 24 hours increased the expression of TNF- $\alpha$ in a concentrationdependent manner. At $100 \mathrm{ng} / \mathrm{mL}$ of LPS, 72.3\% $\pm 3.5 \%$ of CD14+ monocytes produced TNF- $\alpha$. Nonselective $\beta$-AR stimulation with isoprenaline (coincubation with $1 \mu \mathrm{mol} / \mathrm{L}$ ) suppressed this maximal LPS-induced TNF- $\alpha$ expression up to $40 \% \pm 4.5 \%$. This inhibitory effect of isoprenaline on TNF- $\alpha$ expression was concentration-dependent with an $\mathrm{EC}_{50}$ value of $0.1 \mu \mathrm{mol} / \mathrm{L}$. Also, the selective inhibition of PDE4 with rolipram suppressed TNF- $\alpha$ expression up to $58 \% \pm 4.5 \%$ and the direct activation of AC with forskolin suppressed TNF- $\alpha$ expression up to $75 \% \pm 3.8 \%$ (Figure $3 a$ ).

Incubation of PBMCs from healthy volunteers with SEB for 24 hours increased the expression of TNF- $\alpha$ in a concentrationdependent manner. At $10 \mathrm{ng} / \mathrm{mL}$ of SEB, $75.1 \% \pm 3.5 \%$ of CD14+ monocytes produced TNF- $\alpha$. Nonselective $\beta$-AR stim- ulation with isoprenaline $(1 \mu \mathrm{mol} / \mathrm{L})$ suppressed this maximal SEB-induced TNF- $\alpha$ expression up to $25 \% \pm 4.5 \%$. Also, the selective inhibition of PDE4 with rolipram suppressed TNF- $\alpha$ expression up to $75 \% \pm 5.5 \%$ and the direct activation of $\mathrm{AC}$ with forskolin suppressed TNF- $\alpha$ expression up to $85 \% \pm$ $4.5 \%$ (Figure $3 b$ ).

\section{Beta-adrenergic downregulation on CD14+ monocytes in patients with septic shock}

Detailed patient characteristics and critical illness scores are presented in Table 1. All patients received intravenous catecholamines for hemodynamic stabilization. The LPS-mediated TNF- $\alpha$ expression in CD14 ${ }^{+}$monocytes of these patients could not be suppressed by isoprenaline, while forskolin and rolipram inhibited the TNF- $\alpha$ expression in these CD14+ monocytes $(n=20, P<0.001$, Figure 4$)$. These data are an indirect piece of evidence that $\beta$-ARs could be downregulated in CD14+ monocytes of patients with septic shock compared with healthy controls. To elucidate the detailed mechanism of $\beta$-adrenergic downregulation, Western blot analysis of $\beta_{2}$ - 


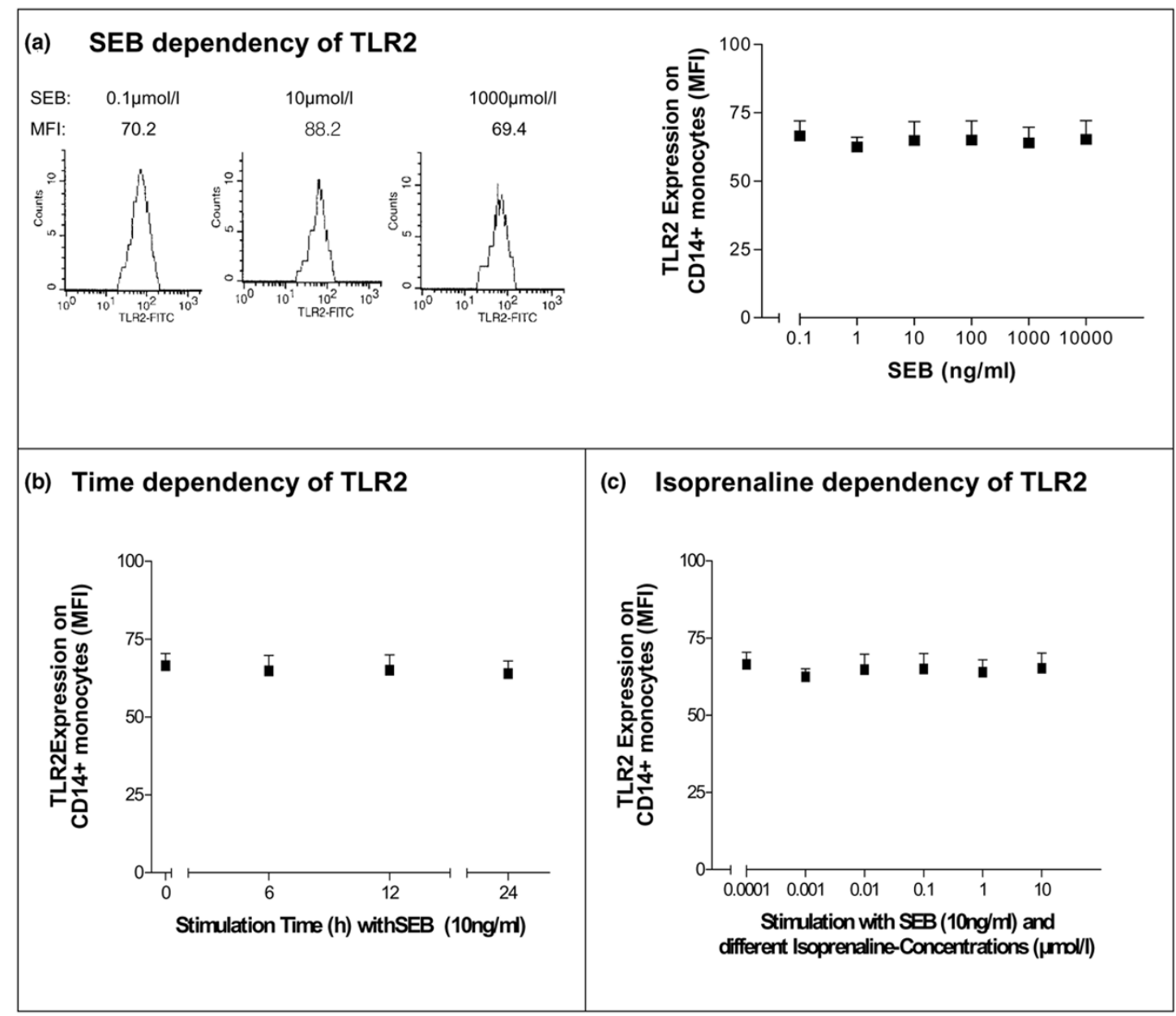

Modulation of Toll-like-receptor 2 (TLR2) surface expression on CD14+ monocytes of healthy volunteers $(n=10)$. Responses to $(a)$ increasing concentrations of Staphylococcus aureus enterotoxin B (SEB), (b) time dependency under continuous SEB stimulation (10 ng/mL), and (c) increasing concentrations of isoprenaline are shown. TLR2 expression was measured by flow cytometry, and histograms of median fluorescence intensity (MFI) and averages with standard error of the mean from all probands are shown. FITC, fluorescein isothiocyanate.

ARs, $A C$, and $G_{s \alpha}$ and $G_{i \alpha}$ were performed. In $C D 14^{+}$monocytes of patients with septic shock, protein expression of $\beta_{2}$ ARs was downregulated by $31 \% \pm 11 \%(P<0.001)$ whereas expression of $\mathrm{G}_{\mathrm{i} \alpha}$ was upregulated by $44 \% \pm 17 \%(P<$ 0.001 ) compared with healthy controls (Figure 5). In contrast, expressions of $G_{s \alpha}$ and $A C$ were unchanged.

\section{Discussion}

The main findings of the study are that, in CD14+ monocytes of patients with septic shock, downregulation of $\beta_{2}$-ARs and upregulation of $\mathrm{G}_{\mathrm{i} \alpha}$ induce $\beta$-adrenergic desensitization. This blunts the catecholamine-induced suppression of LPSinduced or SEB-induced TNF- $\alpha$ release and thus may aggravate the proinflammatory response in septic shock. Since ex vivo incubation with LPS and isoprenaline reproduced $\beta$ adrenergic desensitization in monocytes of healthy volunteers, elevated plasma concentrations of catecholamines and LPS may contribute to $\beta$-adrenergic desensitization in these patients in vivo. Furthermore, the anti-inflammatory response of the PDE4 inhibitor rolipram was maintained, providing a mechanistic rationale for the use of PDE4 inhibitors in PBMCs of patients with septic shock.

In agreement with previous studies [6,12], $\beta$-adrenergic stimulation suppressed the LPS-induced TNF- $\alpha$ expression in a concentration-dependent manner in $\mathrm{CD} 14^{+}$monocytes of healthy volunteers. This effect was mediated by $\beta_{2}$-ARs, but not $\beta_{1}$-ARs, confirming previous observations in human macrophages [19]. Similarly, direct activation of AC by forskolin or inhibition of PDE4 with rolipram reduced LPS-induced TNF- $\alpha$ expression. 


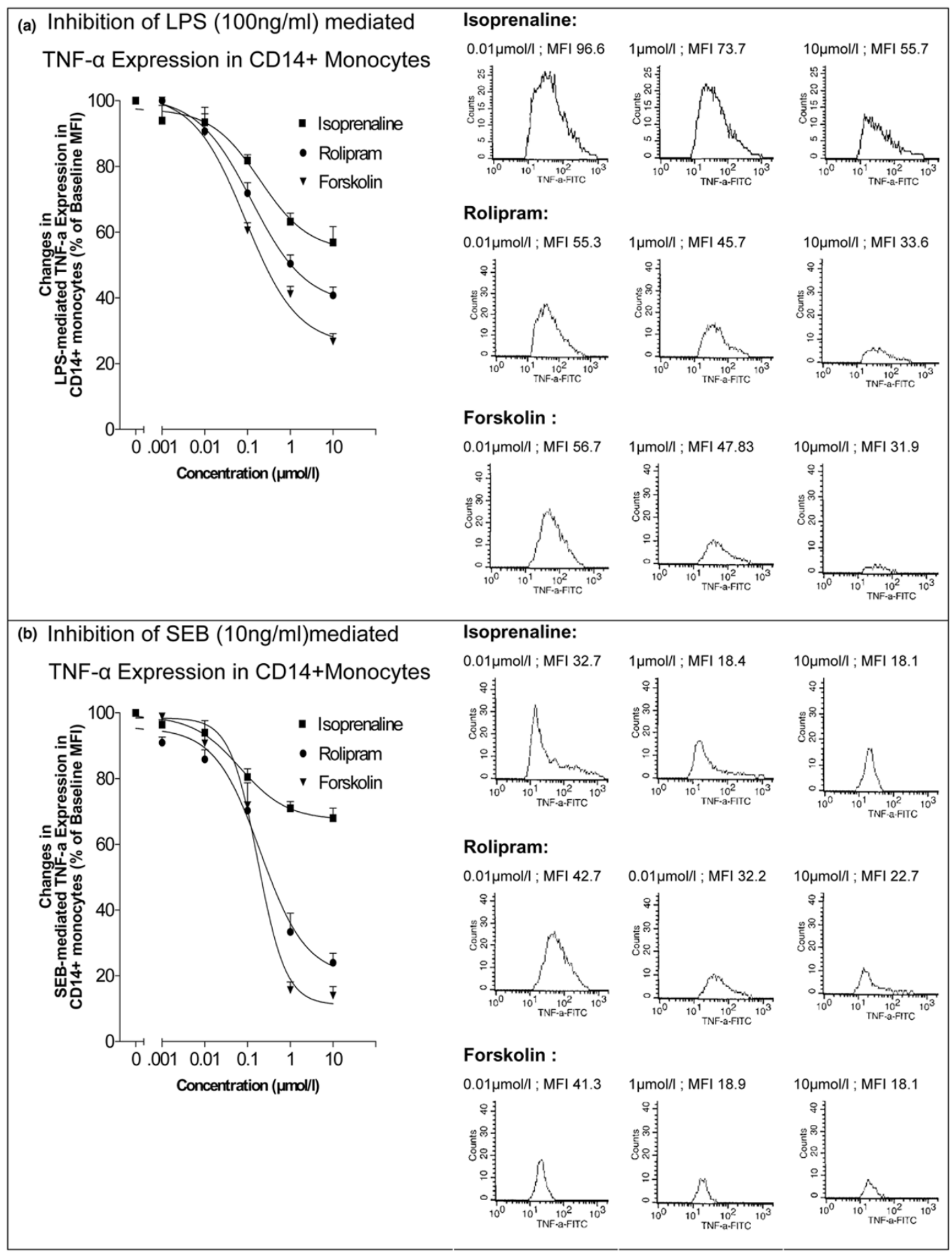

Suppression of lipopolysaccharide (LPS)-mediated or Staphylococcus aureus enterotoxin B (SEB)-mediated tumor necrosis factor-alpha (TNF- $\alpha$ ) expression in CD14+ monocytes of healthy volunteers. Suppression of LPS-mediated (100 ng/mL) (a) or SEB-mediated (10 ng/mL) (b) TNF- $\alpha$ expression in CD14+ monocytes of healthy volunteers $(n=20)$ in a concentration-dependent manner by isoprenaline, rolipram, and forskolin (all 0.001 to $10 \mu \mathrm{mol} / \mathrm{L}$ ) is shown. TNF- $\alpha$ expression was measured by flow cytometry, and histograms of median fluorescence intensity (MFI) and averages with standard error of the mean from all probands are shown. FITC, fluorescein isothiocyanate. 
Figure 4

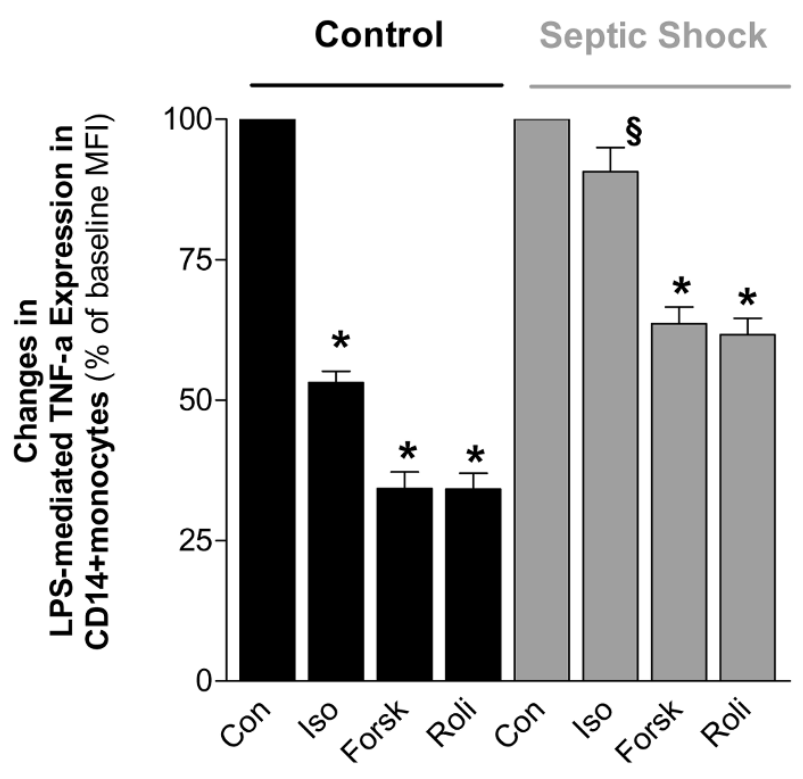

Lipopolysaccharide (LPS)-induced tumor necrosis factor-alpha (TNF- $\alpha$ ) expression in CD14+ monocytes of patients with septic shock and healthy controls. LPS-induced $(100 \mathrm{ng} / \mathrm{mL})$ TNF- $\alpha$ expression in CD14+ monocytes of patients with septic shock $(n=20)$ and healthy controls $(n=20)$ in the absence (Con) and presence of isoprenaline (Iso), forskolin (Forsk), or rolipram (Roli) (all $1 \mu \mathrm{mol} / \mathrm{L}$ ). ${ }^{*} P<0.05$ versus respective control. $\$ P<0.05$ versus Iso in healthy volunteers group.

An important observation of the present study is that, in CD14+ monocytes from patients with septic shock, $\beta$-ARmediated suppression of TNF- $\alpha$ expression was completely abrogated. Previously, Bergmann and colleagues [12] observed that, in the whole blood of patients with septic shock, the epinephrine-induced suppression of LPS-mediated TNF- $\alpha$ release was reduced by only approximately $50 \%$ compared with healthy volunteers. The reason for this discrepancy remains unclear. The use of epinephrine or norepinephrine instead of isoprenaline is unlikely to account for this difference since it has been shown previously that epinephrine-induced stimulation of $\alpha$-ARs does not mediate the suppression of TNF- $\alpha$ release [6]. However, while in our study the use of FACS analysis allowed the estimation of TNF- $\alpha$ expression specifically in CD14+ monocytes, the study of Bergmann and colleagues [12] assessed TNF- $\alpha$ release into the blood from a large variety of potential sources without discrimination of the underlying cell types. Thus, in their study, sources other than monocytes may have contributed to residual suppression of LPS-induced TNF- $\alpha$ release.

Previous studies have not fully resolved the precise mechanisms for $\beta$-adrenergic desensitization of the anti-inflammatory effect of catecholamines in septic shock. Bernardin and colleagues [13] observed that, in PBMCs of patients with severe sepsis, production of isoprenaline-, NaF-, and forskolininduced CAMP was each substantially blunted, suggesting heterologous desensitization of the $\beta$-adrenergic pathway with defects at the level of $A C$. In contrast, we did not observe any changes in the protein expression of $A C$ or $G_{s}$, but downregulation of $\beta_{2}$-AR and upregulation of $G_{i \alpha}$. Upregulation of $G_{i \alpha}$ is in agreement with our previous observation of upregulated $G_{i \alpha}$ expression in human myocardium from patients with septic shock [10]. Importantly, the changed expression of $\beta$-adrenergic signaling components was in concert with the functional effects since both forskolin- and rolipram-induced suppressions of LPS-induced TNF- $\alpha$ release were maintained. These data clearly argue against defects at the level of $A C$ in PBMCs of patients with septic shock, as suggested by Bernardin and colleagues [13].

During septic shock, LPS-mediated or SEB-mediated TNF- $\alpha$ release and elevated catecholamines aggravate $\beta$-adrenergic desensitization, and a vicious cycle of unopposed (catecholamine-refractory) inflammation may develop. The mechanisms of $\beta$-adrenergic downregulation in septic shock are of particular relevance for the development of therapeutic strategies. In animal models of septic shock, treatment with the PDE4 inhibitor rolipram or transgenic ablation of PDE4B [15] ameliorated the inflammatory response of PBMCs and improved survival. However, PDE4 inhibitors have not been tested in humans with septic shock yet, and results from animal models may not be readily extrapolated to the human situation. According to the data of Bernardin and colleagues [13], who found heterologous desensitization at the level of $A C$, one could have expected reduced anti-inflammatory efficacy of rolipram in PBMCs of septic patients. Conversely, in our study, unchanged $A C$ expression and maintained anti-inflammatory efficacy of rolipram provide a mechanistic rationale for the use of PDE4 inhibitors in patients with septic shock. Our findings are limited by missing data about levels of PDE4 (or PDE4 activity) in $\mathrm{CD}_{14}{ }^{+}$monocytes from control subjects and patients with sepsis; these data would strengthen the conclusion that inhibition of PDE4 activity is a potential treatment for sepsis. The clinical use of PDE4 inhibitors is currently limited to patients with depression [20], chronic obstructive pulmonary disease [21,22], and allergic asthma [23].

\section{Conclusion}

This study demonstrates that, in septic shock, the anti-inflammatory effects of catecholamines are blunted by downregulation of $\beta_{2}$-ARs and upregulation of the inhibitory $G$ proteins in CD14+ monocytes. Beta-adrenergic downregulation is overcome by inhibitors of PDE4. These results provide a mechanistic rationale for the therapeutic use of selective PDE4 inhibitors in the treatment of septic shock. Trials to evaluate the efficacy of PDE4 inhibition in septic shock are warranted.

\section{Competing interests}

The authors declare that they have no competing interests. 


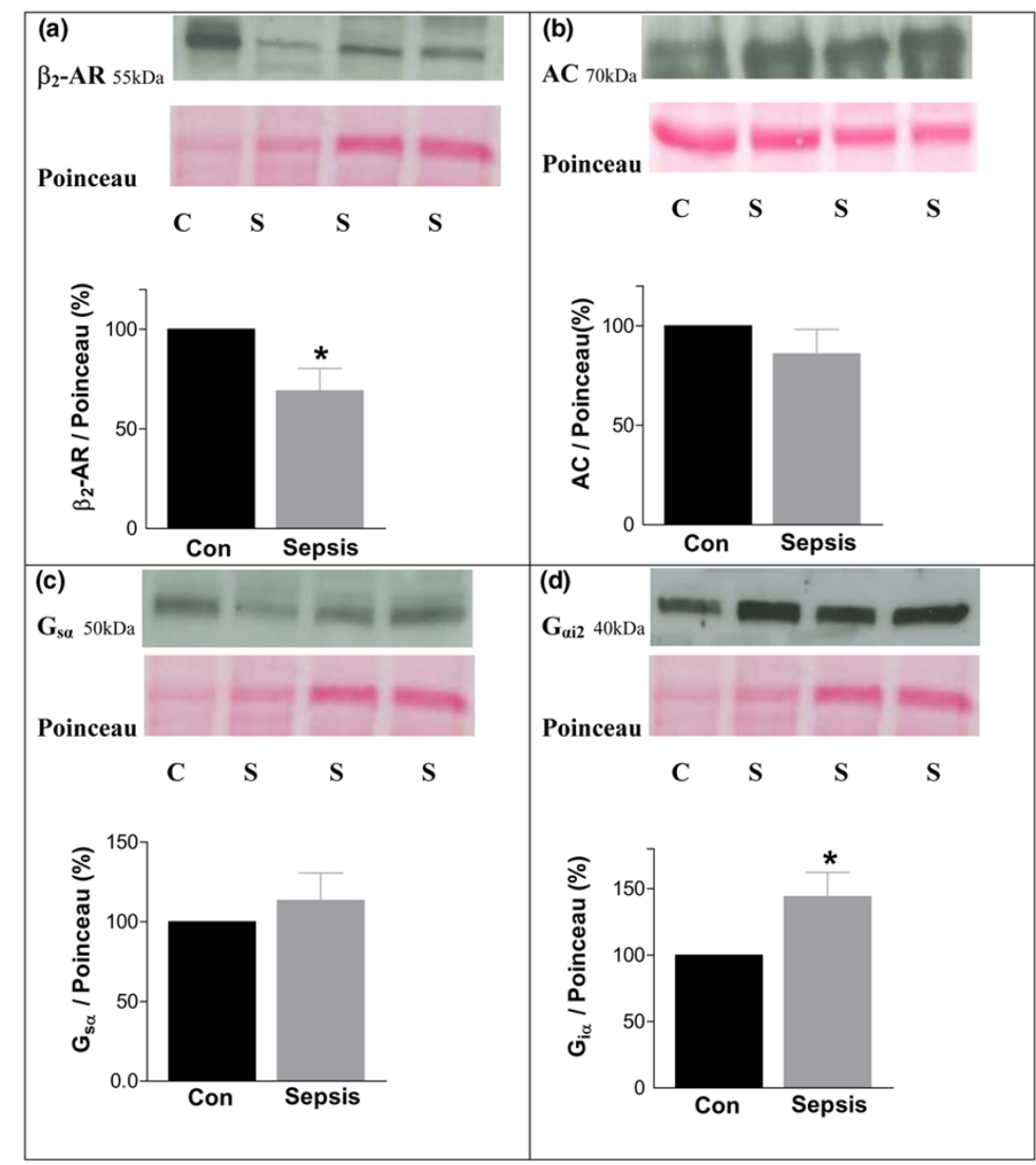

CD14 ${ }^{+}$monocytes of patients with septic shock $(S)(n=20)$ compared with healthy controls $(C)(n=20)$. Immunoblot analysis of protein expression and equal loading of total protein controlled by Poinceau red staining and densitometric quantification are shown. (a) Beta ${ }_{2}$-adrenergic receptors ( $\beta_{2}$-ARs) of membranes, (b) adenylate cyclase (AC) of cytosol, (c) $\alpha$-subunits of stimulatory $\mathrm{G}$ protein $\left(\mathrm{G}_{\mathrm{s} \alpha}\right)$ of membranes, and (d) $\alpha$-subunits of the inhibitory $G$ protein $\left(G_{i \alpha}\right)$ of membranes are shown. ${ }^{*} P<0.001$ versus control. Con, control.

\section{Key messages}

- Anti-inflammatory effects of catecholamines are blunted by downregulation of beta ${ }_{2}$-adrenergic receptors $\left(\beta_{2}\right.$ $A R s)$ and upregulation of the inhibitory $G$ proteins in CD14+ monocytes in septic shock.

- Beta-adrenergic downregulation is overcome by inhibitors of phosphodiesterase 4 (PDE4).

- Anti-inflammatory effects of PDE4 inhibitors are maintained in $\beta$-AR downregulated monocytes in septic shock.

- PDE4 inhibition could be a new therapeutic strategy in the treatment of septic shock.

\section{Authors' contributions}

AL coinitiated the study, participated in experimental investigations and in statistical analysis of the data and interpretation of the data, and drafted the manuscript. MB coinitiated the study. SS and ML participated in experimental investigations. CM participated in statistical analysis of the data and interpretation of the data. All authors read and approved the final manuscript.

\section{Acknowledgements}

We are greatly indebted to Nina Rebmann and Julia Michaely for their excellent technical assistance.

\section{References}

1. Parrillo JE, Parker MM, Natanson C, Suffredini AF, Danner RL, Cunnion RE, Ognibene FP: Septic shock in humans. Advances in the understanding of pathogenesis, cardiovascular dysfunction, and therapy. Ann Intern Med 1990, 113:227-242.

2. Wheeler AP, Bernard GR: Treating patients with severe sepsis. N Engl J Med 1999, 340:207-214.

3. Martin GS, Mannino MD, Eaton S, Moss M: The epidemiology of sepsis in the United States from 1979 through 2000. N Engl J Med 2003, 348:1546-1554.

4. Muzio M, Polentarutti N, Bosisio D, Prahladan MK, Mantovani A: Toll-like receptors: a growing family of immune receptors that are differentially expressed and regulated by different leukocytes. J Leukoc Biol 2000, 67:450-456.

5. Aderem A, Ulevitch RJ: Toll-like receptors in the induction of the innate immune response. Nature 2000, 406:782-787. 
6. Lin WJ, Yeh WC: Implication of Toll-like receptor and tumor necrosis factor alpha signaling in septic shock. Shock 2005, 24:206-209.

7. Annane D, Trabold F, Sharshar T, Jarrin I, Blanc AS, Raphael JC, Gajdos P: Inappropriate sympathetic activation at onset of septic shock: a spectral analysis approach. Am J Respir Crit Care Med 1999, 160:458-465.

8. Bristow MR, Ginsburg R, Minobe W, Cubicciotti RS, Sageman WS, Lurie K, Billingham KE, Harrison DC, Stinson EB: Decreased catecholamine sensitivity and beta-adrenergic-receptor density in failing human hearts. N Engl J Med 1982, 307:205-211.

9. Ungerer $M$, Böhm M, Elce JS, Erdmann E, Lohse MJ: Altered expression of beta-adrenergic receptor kinase and beta 1adrenergic receptors in the failing human heart. Circulation 1993, 87:454-463.

10. Böhm M, Kirchmayr R, Gierschik P, Erdmann E: Increase of myocardial inhibitory G-proteins in catecholamine-refractory septic shock or in septic multiorgan failure. Am J Med 1995, 98:183-186.

11. Silverman HJ, Penaranda R, Orens JB, Lee NH: Impaired betaadrenergic receptor stimulation of cyclic adenosine monophosphate in human septic shock: association with myocardial hyporesponsiveness to catecholamines. Crit Care Med 1993, 21:31-39.

12. Bergmann M, Gornikiewicz A, Sautner T, Waldmann E, Weber T, Mittlbock M, Roth E, Fugger R: Attenuation of catecholamineinduced immunosuppression in whole blood from patients with sepsis. Shock 1999, 12:421-427.

13. Bernardin G, Strosberg AD, Bernard A, Mattei M, Marullo S: Betaadrenergic receptor-dependent and -independent stimulation of adenylate cyclase is impaired during severe sepsis in humans. Intensive Care Med 1998, 24:1315-1322.

14. Prabhakar U, Lipshutz D, Bartus JO, Slivjak MJ, Smith EF, Lee JC, Esser KM: Characterization of cAMP-dependent inhibition of LPS-induced TNF alpha production by rolipram, a specific phosphodiesterase IV (PDE IV) inhibitor. Int J Immunopharma$\mathrm{col}$ 1994, 16:805-816.

15. Jin SL, Lan L, Zoudilova M, Conti M: Specific role of phosphodiesterase 4B in lipopolysaccharide-induced signaling in mouse macrophages. J Immuno/ 2005, 175:1523-1531.

16. American College of Chest Physicians/Society of Critical Care Medicine Consensus Conference: definitions for sepsis and organ failure and guidelines for the use of innovative therapies in sepsis. Crit Care Med 1992, 20:864-874.

17. Link A, Ayadhi T, Böhm M, Nickenig G: Rapid immunomodulation by rosuvastatin in patients with acute coronary syndrome. Eur Heart J 2006, 27:2945-2955.

18. Böhm M, Larisch K, Erdmann E, Camps M, Jakobs K, Gierschik P: Failure of [32P]ADP-ribosylation by pertussis toxin to determine Gi alpha content in membranes from various human tissues. Improved radioimmunological quantification using the 125I-labelled C-terminal decapeptide of retinal transducin. Biochem J 1991, 277:223-229.

19. Izeboud CA, Mocking JA, Monshouwer M, van Miert AS, Witkamp RF: Participation of beta-adrenergic receptors on macrophages in modulation of LPS-induced cytokine release. J Recept Signal Transduct Res 1999, 19:191-202.

20. Hebenstreit GF, Fellerer K, Fichte K, Fischer G, Geyer N, Meya U, Sastre-y-Hernandez M, Schony W, Schratzer M, Soukop W: Rolipram in major depressive disorder: results of a double-blind comparative study with imipramine. Pharmacopsychiatry 1989 , 22:156-160.

21. Rabe KF, Bateman ED, O'Donnell D, Witte S, Bredenbroker D, Bethke TD: Roflumilast - an oral anti-inflammatory treatment for chronic obstructive pulmonary disease: a randomised controlled trial. Lancet 2005, 366:563-571.

22. Calverley PM, Sanchez-Toril F, Mclvor A, Teichmann P, Bredenbroeker D, Fabbri LM: Effect of one year treatment with roflumilast in severe chronic obstructive pulmonary disease. $\mathrm{Am} J$ Respir Crit Care Med 2007, 176:154-161.

23. Timmer W, Leclerc V, Birraux G, Neuhauser M, Hatzelmann A, Bethke T, Wurst W: The new phosphodiesterase 4 inhibitor roflumilast is efficacious in exercise-induced asthma and leads to suppression of LPS-stimulated TNF-alpha ex vivo. J Clin Pharmacol 2002, 42:297-303. 